\title{
Housing Flexibility: A Framework for a Quantitative Evaluation Method due to Turkish Designers
}

\author{
Hatice Kalfaoğlu Hatipoğlu 1๑ , Salah Haj Ismail ${ }^{2} \odot$
}

\begin{abstract}
${ }_{1}^{1}$ Assistant Professor, Faculty of Architecture \& fine Arts, Ankara Yildirim Beyazit University, Ankara, Turkey. (Principal contact for editorial correspondence.) Email: hhatipoglu@ybu.edu.tr
\end{abstract}

${ }^{2}$ Associate Professor, Faculty of Architecture \& fine Arts, Ankara Yildirim Beyazit University, Ankara, Turkey. Email: hhatipoglu@ybu.edu.tr

\begin{abstract}
Purpose

Flexibility became an important factor affecting the quality of housing projects in Turkey nowadays due to the requirement of the permanent mobile/dynamic lifestyle. Thus, a responsive housing design should be developed to allow modifications that respond to the changing demands of the tenants through time. Although it is a major debate in housing design for many years in western countries; the Turkish perspective of housing ignores the adjustment to changing needs and compensates it with big-sized dwellings, causing space consumption. This contradicts with the Turkish roots emerged from the nomadic lifestyle with the tent. Housing flexible design is an essential requirement in Turkish culture historically. This study aims to develop a quantitative evaluation method, in order to assess the level of flexibility, defining the indicators and the hierarchy to measure it.
\end{abstract}

\section{Design/Methodology/Approach}

In order to establish a Flexibility Assessment System, Value Engineering method is applied, a tool used in decision-making process to choose the ideal solutions. Additionally, this system will contribute to the improvement of the "architectural quality of housing" in Turkey, since now it is evaluated and commercialized merely by the calculations of the surface areas.

\section{Findings}

Despite that most of the experts have a different understanding and evaluation of flexibility, they concurred on some indicators to measure and evaluate flexibility. Moreover, this study has created a clearer definition of the terminology of flexibility from the point of view of Turkish society and provided basic guidelines for the implementation of flexible housing design.

\section{Research Limitations/Implications}

Quantifying a complex design parameter as flexibility using the Value engineering method requires the division and analyse the opinion of expert separately from the end users' opinion.

\section{Originality/Value}

This study is the first study defining the criteria of flexibility, and their quantitative evaluation from Turkish cultural view. Moreover this study creates a more clear definition of the terminology of flexibility from the point of view of Turkish society and provides basic guidelines for the implementation of flexible housing design.

Keywords: Flexibility, housing quality, housing, assessment system, housing design, sustainability 


\section{INTRODUCTION}

The technological, economic, cultural transformations have impacts on our socio-cultural structures as well as activity patterns. Housing should allow adjustments for various stages of human life due to the changing social and demographic circumstances (Habraken, 2019; Hasgül \& Özsoy, 2016; Idrissi, 2006; Schneider \& Till, 2016). According to the statistics of Tuik 2011 (Tuik, 2016)(Figure 2), 67\% of the householders in Turkey are owners of their houses. This means that they do not consider them as temporary houses, contrarily they plan to live for a long-term in these houses. The social and demographic changes in the people's life, as mentioned in details later, requires the inhabitants to have a high level of flexibility in their houses. These changes in lifestyle have substantial influence on housing design regarding sizes and types. Considering that Turkish societies coming from the nomadic lifestyle, starting with the tent, the Turkish housing design should respond to these changes conveniently. While flexibility is not a real design consideration in Turkey, there are current debates and implications in western societies taking place for a long time. In Turkey, residents do not consider possible interventions when more space is needed, instead they seek big-sized dwellings from the beginning; which is the principle that current Turkish housing design is based on. Most of the houses in Turkey have at least three rooms, and there is no tendency to change those dwellings, even the number of users decreased to two after demographic changes, due to the inflexibile houses and mentality of people (Figure 1). This housing perspective ignores the adjustment to changing needs and patterns(Akalin \& Yildirim, 2010; Altaş \& Özsoy, 1998).

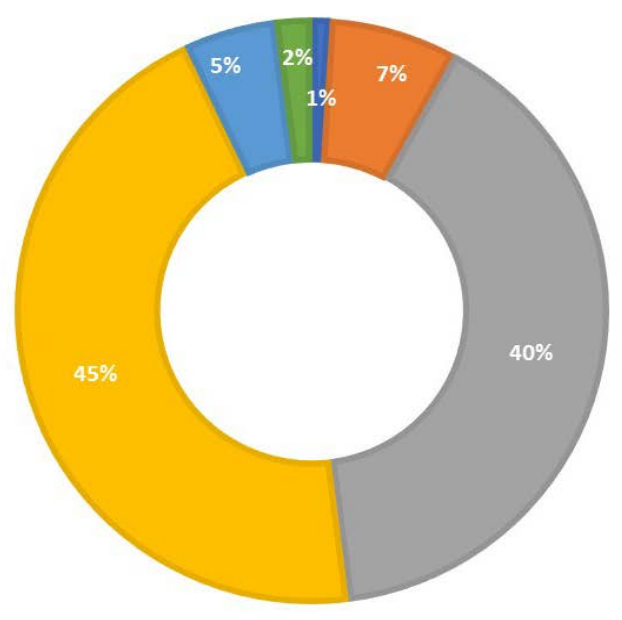

dwelling with 1 room

dwelling with 2 rooms dwelling with 5 rooms dwelling with 3 rooms adwelling with $6+$ rooms
Figure 1. Households by number of rooms in dwellings in 2011 in Turkey (Tuik, 2011)

Moreover, these standard big-size dwellings cause a space consumption. The average number of people per room (including the living room, 
except the kitchen, bathroom and toilets) was calculated as 1.1 (Tuik, 2016). Comparing this value with European countries, it is an unsustainable result related to the ecological footprint when considering the change in the number of users in the dwelling. Architects have to shed light on this tendency because it contradicts with the concept of sustainability that aims to reduce damage and footprint on the environment (Kendall, 1999; Mahdavinejad et al., 2012; Sposito, 2012). In order to create a shift from an understanding which forces people to adapt to the predefined housing structures, to the demonstration of a housing design that provides freedom to change living spaces through its adaptation and flexibility.

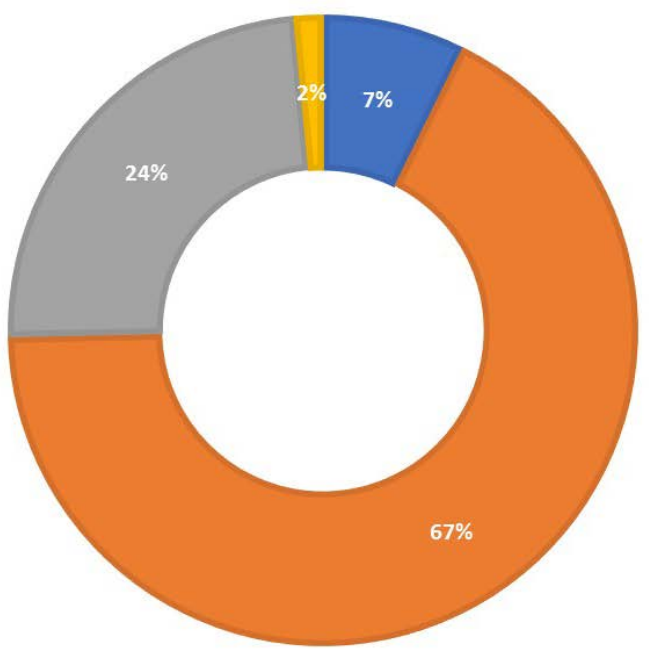

Figure 2. Property status of households in housing (Tuik, 2011) not owner but not paying rent a nouse owner a renter a lodgement

Accompanied with different typologies, flexibility provides the adaptability to the changing circumstances; which provides the possibility of various modifications of houses. This enables a more flexible lifestyle instead of today's fixed housing units that forces people to change their habits/rituals and adapt themselves to the building forms (Schneider \& Till, 2005). It is observed that the importance of the size/number of rooms in the residential units increases. Correspondingly, architectural practices in cities pursue quantity instead of quality, which flexibility contributes. On one hand, this minimizes architectural quality, and on the other hand, it hinders the upholding of environmental values and sustainable approaches. Minimising the sizes of dwellings with smart solutions, which is possible with flexible design, reduces our carbon footprint and the damage to environment coming from the construction boom (NJ, 2009). These smart solutions are related to flexibility, because the expression of efficiency for a functional planning can be successful if it is capable of enduring through time. Flexibility is more than false neutrality, as Forty described, and should be 
combined with concepts such as participation, sustainability, efficiency of planning etc. (Forty, 2002; Kendall, 1999; Mahdavinejad et al., 2012).

Although there are some studies related to flexibility of buildings, the assessment of flexibility and the relation of socio-cultural backgrounds and housing conditions forms gaps in these researches (Estaji, 2017). Because of the importance and benefit of flexible design, this study aims to create a guideline for the design of the flexible housing in different scales by determining the indicators and the hierarchy between them quantitatively. This reveals the potentials for the implications of flexible housing. Value assessment of flexibility in housing provides also awareness and base for practical goals (Van der Voordt \& Van Wegen, 2005). This understanding leads to the interpretation of the evaluation results into clear definition and rating of the criteria of a complex decision-making process. The previous quantitative assessments of flexibility are either global, ignoring the perspective of culture, or developed qualitatively and partially lacking the holistic view of flexibility as discussed later in details (Hasgül \& Özsoy, 2016; Idrissi, 2006; İSLAMOĞLU \& USTA, 2018; Moharram, 1998; Rajan et al., 2003). Hence, the authors think that this study demonstrates an approach which provides both a holistic view with a local cultural character of the assessment of flexible housing.

\section{LITERATURE REVIEW}

\section{a. Definitions of Flexibility}

Flexibility means the easy adjustability of an aspect of a system (Fricke \& Schulz, 2005). In this system, different changes can be realised in any time cost-effectively in order to respond to the changing requirements at different times (Saleh et al., 2003). Flexibility is a crucial parameter in architectural design especially in the field of housing. Because of the complexity and variability of the relationship between users and spaces in residential areas, the response to the changing needs of the tenants is a key factor for life quality (Van der Voordt \& Van Wegen, 2005; Zivkovic \& Jovanovic, 2012). According to Rapoport, physical elements are more important than creating visual and cultural categories, so it makes sense if they provide an engagement with user schemes (Rapoport, 1982). Moreover, behaviour-adaptation theories investigate the dual adaptation between space and user. Behavioural differences for change link the environment and behaviour (Altman \& Wohlwill, 2012; Habraken, 2019; Hasgül \& Özsoy, 2016; Till \& Schneider, 2005). That means the harmony and adaptation between the space and user has a great importance for the social quality.

Flexibility in housing design provides tenants with the possibility of adaptation according to the changes, while providing architects with the vision of the future scenarios of their designs. The designing process is very important for flexibility. The Austrian architect Ottokar Uhl describes this importance indicating that the success of an architect is not 
Housing Flexibility: A Framework for a Quantitative Evaluation Method due to Turkish Designers

just by deciding the form, but also by the close relation with the processes of designing and building (Steger, n.d.).

There are many social and design quality reasons, but another motivation for flexibility is the economic benefits in long term. There is few data about this argument, but qualitative studies reveal that if the technology, strategies and spatial principles of flexibility are applied, the buildings in turn will sustain longer and provide cost savings (Cristiana Cellucci \& Michele Di Sivo, 2015; Schneider \& Till, 2005; Slaughter, 2001; Zairul \& Geraedts, 2015). Moreover, according to the studies related with long life costs (LLC), the spatial adaptability and flexibility implementations have a positive effect increasing user satisfaction (Altaş \& Özsoy, 1998; CABE, 2004; Uhl, 1981). Consequently, the justifications for flexibility importance can be classified into different reasons, mainly derived from Users, Environment, Social, Cultural and the constructive resources as follows:

1. Users: when discussing flexibility with final users of housing projects; their main reasoning for the need of flexibility were firstly, Function, due to the changing requirements through time related with function (Habraken, 2019; Stephen \& Jonathan, 2010; Till \& Schneider, 2005). In addition, the need to maximise the efficient use of the space. Secondly, Physical need, with the changes of physical conditions of users in time, such as limited mobility for getting older, some accidents... Flexibility allows the modifications for the new needs (Hasgül \& Özsoy, 2016; Rabeneck et al., 1974). Thirdly, the change of user, different requirements are created when a new user is moving in, which directly refer to flexibility.

2. Environment: with the challenges created by Climate Change, flexibility is needed more than ever. Especially with the change of seasons' cycle; which induces other conditions. Turkey is a country that has a seasonal heat difference amongst different regions, and generally, the construction type applied over Turkey does not tackle this factor effectively. Huge amount of energy consumed for heating in winter and cooling in summer due to the lack of design precautions. The design flexibility may contribute to tackle this problem.

3. Social factors, which are beside the structural factors, are the main reasons that make flexibility an important parameter of architectural design in Turkish society. This includes different sub-factors such as Family size, since the expansion of families through time needs extra rooms, and the separation of males and females is an important criterion in Turkish community. After the growth of the family members, they leave the house and the number of the family decreases, which results in less space/room need. Flexible design would be a solution to avoid moving out, or occupying more space than needed. Another important factor is the Cultural background, in Turkey there is a mobile family structure. There are still families living as one big family with parents and grandparents. According to the housing conditions, they may keep on 
living together, or forced to live separately. Moreover, old people in late stage of their lives, move to their children' houses in some cases, because of their disabilities or need for care. Thus, flexibility would be a solution for the efficient use of space during the different changes and different periods of family life. Additionally, the social relations and statues play a role in flexibility needed, because the change in social status motivates people to make changes and upgrade living spaces.

4. Building (Infrastructure): Usually the developments in technology and new techniques stimulate people to make changes in their accomodation. Besides the updating needs, buildings need periodic Maintenance, due to building degradations in time. This sometimes also leads to Upgrading the building to be smarter and responds to the upgrading of social positions of people, in order to reflect the new social image of the users. Flexible designs contribute to make this process more feasible.

Despite the fact that flexibility is the adaptability to the changing requirements and patterns of users across time, this definition is very broad and complex which cannot be easily comprehended. Housing flexibility is defined as both being capable of choices regarding construction and social characteristics and responding to the changes during different life stages of the building (Schneider \& Till, 2005). Consequently, this kind of housing ensures multifunctional use of space, changeability and chance for configurations for the most appropriate and convenient preferences due to the participation in the design phase (Groak, 2002; Rabeneck et al., 1974). Various alternative interpretations can be derived respecting the provided creative borders (Koolhaas, 1998). Herman Hertzberger indicates that "We must continuously search for archetypal forms which, because they can be associated with multiple meanings, can not only absorb a programme but can also generate one" (Hertzberger, 1991).

In modern architecture, open plan type has been accepted as one of the prominent ways of flexible housing design. However, this neutrality is discussed whether it has been a limit for the architectural design. According to Adrian Forty the neutrality in design is overemphasized; because he thinks that if a glove can fit to all hands, therefore it becomes no hand (Forty, 2002). Although neutrality as a type of providing flexibility criticised with the absence of identity and lack of distinctive features of the building type, flexibility in housing, which can be provided with various applications in design, is an important and needed requirement in today's mobile lifestyles. Flexibility has been a real concern after the 1950s in Europe, and the ways for achieving it has been comprehensively discussed. These multiple methods including revisions can also provide a base for the argument of flexibility in Turkish housing. The polyvalence of a space, producing optimal solutions by providing various scenarios with little interventions in the form, is important for the Turkish society coming from nomadic lifestyle. Moreover, the separation 
of space with movable partitions and furniture, which provides a conversion in the space, already exists in the generic corollary of the environment (Venturi, 1977). The most prominent approaches of creating flexibility in housing are neutralisation and indetermination of space, inclusion of independent and modular elements, creating permanent or contemporary units with divisions, implementation of portable/adjustable furniture, creating a hierarchy and relation among spaces, efficient solution of service and technical areas (De Paris \& Lopes, 2018).

Consequently, there are different methods of achieving flexibility which means considering long term thinking (Cristiana Cellucci \& Michele Di Sivo, 2015). Till and Schneider indicates that flexible housing should provide choice in terms of social use and construction both at the design stage and during its lifetime. In order to provide flexibility during the lifetime, the consideration in the design phase is an important criterion(Schneider \& Till, 2016). For this reason, it is crucial to determine the principles or criteria that facilitates flexibility. If it is possible to analyse the degree of flexibility in planning, this may guide the planners for a flexible design too.

\section{b. Measurement of Flexibility}

Analysing and defining the value of design concepts, such as flexibility, has always been a complex process due to various indicators. The studies to quantify the evaluation of flexibility in housing design are few, most of the studies are qualitative and descriptive rather quantitative. Moreover, these studies are not performed in Turkey analysing Turkish housing design, as came to our knowledge. On the other hand, value is a subjective term and changes according to the background, needs, culture and preferences of different societies. Leung describes the solution of this complexity with the model of value management towards a behavioural paradigm. Concept of value has been defined according to the theoretical context such as needs, beliefs, attitudes and preferences. Number of alternatives have been described for the decision process (Leung \& Liu, 2003). With the help of this value management, the objectives' expectations of the clients are better-satisfied (Connaughton \& Green, 1996; Male et al., 1998). Most of the conflicts are stimulated and solved with a decision-making process including value specificity and formation of these values into goals(Leung \& Liu, 2003).

To assess the flexibility, it is important to define the principles of flexibility. There have been many attempts to describe these principles. Stamm suggested a system of structural and design principles for the post occupants or multi-usability, which assumes walls as furniture (Beisi, 1995). Technology is an important element providing services of configuration for flexibility. According to Habraken and the Open Building movement in modernism, the use of modern construction techniques and 
prefabricated elements provides flexibility (Stephen \& Jonathan, 2010). Frame structures were introduced as the most adequate form of construction allowing the change over time (Schneider \& Till, 2016). Nevertheless, many other parameters affect the degree of flexibility. The additional elements, which help to divide the space, also configure the flexibility of the space. The design of Günther Domenig in Graz is an example of an inflexible housing despite its potential and consideration for flexibility (Domenig, 1991). The problem was the complexity of the geometries, which restricted the change since its construction. That means there are different dimensions of flexibility that should be considered as a whole.

In order to make principles of flexibility more concrete, there are several studies for the assessment of flexible housing. Kiaee et al. measures the flexibility of the housing spatial system, using the space syntax in different patterns in Qazvin (Kiaee et al., 2019). Although this method is based on analytical and logical methods, it focuses on spatial arrangement methods using visual connectivity, permeability and circulation that lacks the consideration of materiality and structural constructional indicators. Another quantitative study about flexible housing on chosen case studies in Morocco by (Idrissi, 2006) was conducted. This study includes an index based on the functional area of the cases after the alterations made by users. Rajan et al. explained a clear ranking system to evaluate flexibility in their paper "Design for flexibility- measures and guidelines", which suggests design guidelines for the flexible design in Swedish society (Rajan et al., 2003).

In Turkey, (Nal \& Ünlü, 2009) conducted research about flexibility provided by an open plan system focusing on constructional features of permanent houses in Düzce. Another study aiming for a decision making process in housing based on the preferences of the tenants is the research of (Koman \& Eren, 2010), which is based on different usage of space related with the dimensions of the dwelling units and number of occupants. Both studies demonstrate the layout differentiations regarding participation and focus on just one part of flexibility: plan diversity and adaptability.

Özsoy and Hasgül developed a design matrix, which is more a qualitative discussion on different housing typologies about flexibility, provided a comparison of the selected projects hierarchically and defined three levels of flexibility degree (Hasgül \& Özsoy, 2016). Another evaluation system is the study of Altas and Özsoy that is an assessment based on the frequency of responses of tenants adaptability which doesn't include a multifactorial analysis (Altaş \& Özsoy, 1998).

These evaluation systems lack a holistic approach that considers all of the indicators together and evaluates them quantitatively. It is also important 
Housing Flexibility: A Framework for a Quantitative Evaluation Method due to Turkish Designers

to understand the hierarchy between these indicators in order to ensure a flexible housing design.

In this context, flexibility is assumed as a quality in the designing and building process in this study. It is possible to assess this quality in a quantitative way with decision-making tools. Providing housing flexibility, which demonstrates adaptation to the changing requirements of the tenants in several phases of their life, contributes to the improvement of the "architectural quality of housing" in Turkey in a wider sense, which is evaluated and commercialized merely according to the calculations of surface areas.

\section{The Indicators of an Evaluation System for Flexibility in Turkish Housing Design (Evaluation for Housing Flexibility -EHF) on Unit and Building Scale}

From the literature review, interviews with experts of architectural design in Turkey and analysing them, the authors suggest the following three criteria and their sub criteria to assess flexibility from the Turkish cultural and social point of view.

1. Adaptability: According to (Schneider \& Till, 2005) adaptability is the design of the space so that it can be used in different ways and it covers "polyvalence" which is described especially by Dutch theorists as the capability of space that ensures multiple ways of different implementations usually applied without physical interventions. Moharram indicates that adaptability provides the ability of individual modifications to adjust new conditions and covers internal changes such as subdivision and the combination of spaces. Moreover, adaptability is the adjustability of space, which ensures the general target of a group instead of a particular target. If a space is adjustable/adaptable, it is designed in such a way that allows easy and cheap adaptation for people with disabilities or different needs when required (Van der Voordt \& Van Wegen, 2005). As a result, adaptability is the easy adjustability of space according to changing conditions and requirements, which also includes open plan design.

Although some architects classify flexibility and adaptability as different criteria, adaptability is embedded in flexibility and is accepted as a method for flexibility in this study. The suggested sub criteria of adaptability are:

1.1. Furniture: If different furnishing were possible in the space, the space would be adaptable for different needs.

1.2. Proportion: Proportion of the room size decides the grade of adaptability. For example; while a narrow and long room is difficult to be adapted for different uses of space, a better proportioned/size balanced room, closer to square shape, contributes better to adaptability.

1.3. Neutrality (form): Neutrality of the form that allows a certain indeterminacy also allows a better adaptation of the space for different conditions while determinant forms allow it less. 
1.4. Architectural components: Availability of architectural components creating partition or combination of spaces easily when needed, such as sliding doors etc., contributes to adaptability.

1.5. Adding/removing: Capability of adding/removing elements in the space when needed provides adaptability of space. (For instance; Adding a lift when needed, or creating space for prams when needed)

2. Multifunctionality: The space Multifunctionality is defined as being suitable for different functions without making changes to the structures of built-in features (Van der Voordt \& Van Wegen, 2005). Moharram describes multifunctionality with the term of 'versatility' and relates it with two variables; space and time (Moharram, 1998). Multifunctionality is referred to space, which is used for several functions at the same time or for different functions at several times. This covers the neutral function of the room. This type of flexibility is the most practical available way of flexibility. It is not usual for the structure and construction technology to be flexible. The suggested sub criteria of multifunctionality are:

2.1. Neutrality (No function): Undetermined functions of the rooms allow more flexibility.

2.2. Furniture (different functions): Movable furniture supporting different functions of the space contribute to multifunctionality of rooms.

3. Variability: It is the capacity for the extension and contraction of space. It allows changes to be made to size/dimensions, form, location etc. (Van der Voordt \& Van Wegen, 2005). It can be described as the usage of the potential of the space with some interventions. When compared with adaptability, variability requires more structural, formal, and hard applications. According to (Till \& Schneider, 2005), 'soft' represents implementations providing a certain indeterminacy and 'hard' represents elements which specifically determine the potential of the spaces in the future. The sub criteria of variability are described as follows:

3.1. Opening of the walls: The more opening letting the light into the room, the more efficient the area used and different functions allowed.

3.2. Shape of circulation: The shape of circulation routes (linear or square/rectangular) affects variability.

3.2.1. Unit scale (linear or square / rectangular)

3.2.2. Building scale (walk up type with 2,4 or more units or single/double corridor type)

3.3. Versatility/Modification (extension-contraction): It is important that the dwelling/building plan convenient to make extension and contraction to achieve modifications in sizes. A neutral plan or neutral access with respect to the equipment and size of the rooms contributes to versatility.

4. Structure and construction

There is a strong reciprocity between construction techniques and flexibility, and most of the housing schemes are built with simple and 
Housing Flexibility: A Framework for a Quantitative Evaluation Method due to Turkish Designers

robust construction techniques in order to provide the possibility of future intervention (Schneider \& Till, 2005). The arrangement of columns and load bearing walls is very crucial to obtain an efficient space that allows possible changes in the future. The skeleton construction system with non-load bearing walls provides an independent and flexible plan (Darke, 1982; Dirisamer et al., 1976; Rabeneck et al., 1974). The open space introduced by early Modernism provided larger spaces including light partitions due to the new constructional systems. The arrangement of the technical installations such as clean/dirty water, heating system etc. have also an important influence on housing flexibility (Zairul \& Geraedts, 2015). The Residential Open Building idea also derived mostly from the technical achievements with accompanying design (Stephen \& Jonathan, 2010). For a flexible design, it is important to establish a specialised categorisation of construction layers like services, structure, envelope, internal partitions etc. (Habraken, 2019).

4.1. Position of wet spaces: Position of wet spaces affects other places is crucial for the use of space. The accumulation or smart solution of wet spaces in the plan affects the potential flexibility.

4.2. Type of load bearing system (masonry/skeleton): Skeleton system is accepted as more flexible because the system allows modifications in space.

4.3. Divisions (flexibility): The character and positions of the divisions of the units, such as separation of load-bearers from inbuilt elements, usage of demountable walls, and the general grid size of the shell, influence flexibility.

4.4. Material: The material of vertical divisions is crucial for flexibility. The capability of these materials to be easily retrofit or moved decides the potentials of flexibility.

4.5. Technical services (fire, escape, electricity): Position and location of technical services and their radius of influence might limit flexible design and configuration.

Table 1 summarizes all the criteria and sub-criteria analysed in the paper:

Table 1: Suggested Criteria and sub criteria for the assessment of flexibility value

\begin{tabular}{|c|c|c|c|c|c|c|}
\hline$z \underset{\oplus}{\stackrel{\oplus}{\oplus}}$ & $\begin{array}{l}3 \\
\stackrel{3}{0}\end{array}$ & \multicolumn{5}{|c|}{ Sub Criteria } \\
\hline 1 & 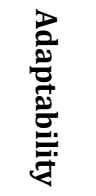 & 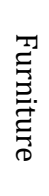 & $\begin{array}{l}0 \\
0 \\
0 \\
0 \\
0 \\
0 \\
0 \\
0\end{array}$ & 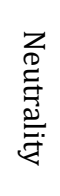 & 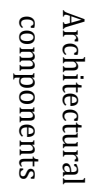 & 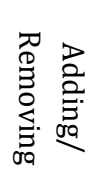 \\
\hline 2 & 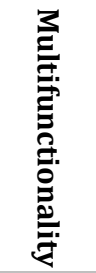 & 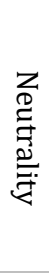 & 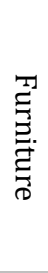 & & & \\
\hline
\end{tabular}




\begin{tabular}{|c|c|c|c|c|c|c|}
\hline 3 & 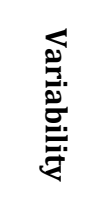 & 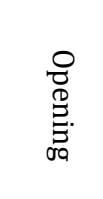 & 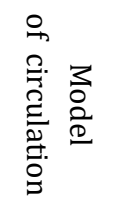 & 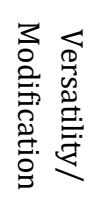 & & \\
\hline 4 & 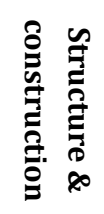 & 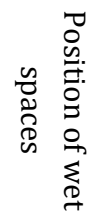 & 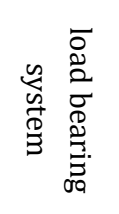 & 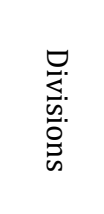 & $\begin{array}{l}3 \\
\frac{3}{0} \\
\frac{0}{0} \\
\frac{3}{2}\end{array}$ & 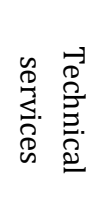 \\
\hline
\end{tabular}

\section{RESEARCH METHOD}

This paper suggests a multi-criteria methodology for the assessment and evaluation of the flexibility in the designs of Turkish housing projects. Targeting the decrease of life cycle cost of housing by decreasing and easing the modifications needed by the user, through the implementation of systematic structure of Value Engineering (VE).

Since VE is controlling the triangle vertices of management including performance, quality and cost, enhancing the value of any will increase the value of the others. While one allows the identification of where cost reduction could be achieved, the other shows the targets to be achieved to guarantee the long-term profitability plan of a design. In order to do that, an assessment system was developed, with the application of the VE procedures at four subsequent levels: Adaptability, Multifunctionality, Variability, Structure and construction.VE is applied in order to contribute to conclude on the right decisions for the targeted purposes. (Connaughton \& Green, 1996; Male et al., 1998). A value engineering study includes three stages (see Figure 3)

A pre study stage, where the data is collected through a literature review and interviews with both experts and users, in order to define the needs and model the system. The authors, in the aforementioned chapters, have applied to define flexibility and its criteria in Turkish culture and society. In this paper, it will be defined mainly according to experts in the field, architects, planners and designers. A future study will define the criteria from the user's point of view, to understand the compatibility and mutual understanding between the user's needs and the designer's understanding.

The VE stage is a workshop where the information is introduced to the evaluators, to analyse the functions, mainly to define the parameters, which control our assessment of a flexible design. This is the stage developed, analysed and presented particularly in this paper.

The post study stage where the results are presented, and the Assessment system is implemented to different case studies, which will be presented in future studies. 
Figure 3. Three main Stages of VE

Figure 4. Several phases of $\mathrm{VE}$ from the collection of information to the implementation
2

3

Information

Function Analysis

Idea Generation

Evaluation

Development

Presentation

Pre-Study

VE Workshop

Post-Study

A job plan of the VE stage involves seven phases for transforming assigned specific values (from the client) to (participatively set) specific goals (Figure4)

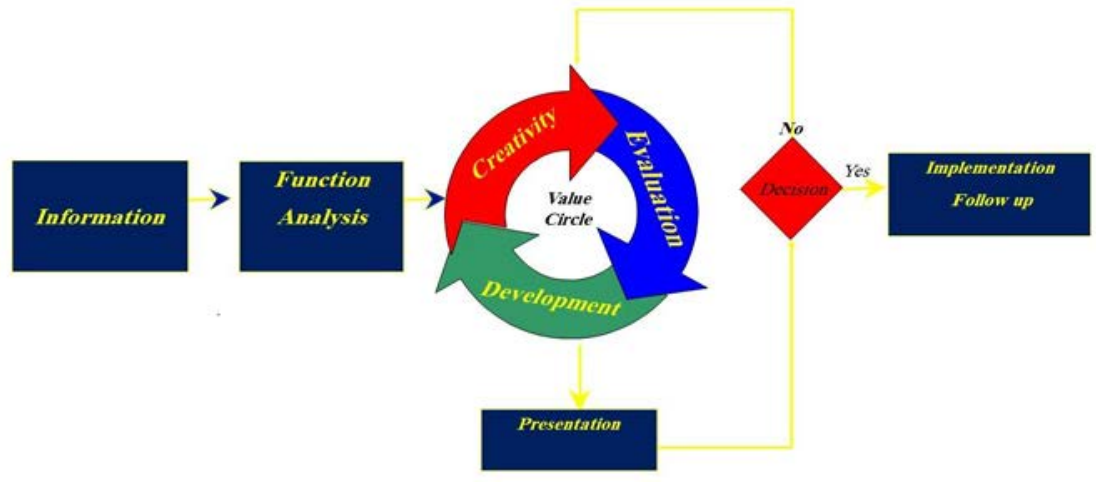

After the collection of the information from different resources, interviews and analysis, the definition of Flexibility and the important factors and concepts of architectural design affecting and controlling its level, are determined.

Then a function analysis is applied. VE method calculates the value of each indicator asking a group of experts to compare the suggested criteria reciprocally. Using the following logic Comparing Criteria $\mathbf{A}$ with B: If $\mathbf{A}$ is $\boldsymbol{X}$ times more important than $\mathbf{B}=(\boldsymbol{X A})$,

If $\mathbf{A}$ is equally important as $\mathbf{B}=(\mathrm{AB})$,

If $\mathbf{B}$ is $\boldsymbol{X}$ times more important than $\mathbf{A}=(\boldsymbol{X B})$

The number of times for each criterion repetition, is summed, nd the medium of the different experts ranking is calculated

Value of $A=\sum X \mathbf{A} /$ N.experts. .This will define the value of Functions in the System. When it is implemented to measure the flexibility of a house design, the ranking will be given by evaluators for each indicator as: $5=$ excellent, $4=$ very good, $3=$ good, 2 = fair, $1=$ poor, thus the value of Quality will be defined. Subsequently, each design will have its value of Flexibility by applying the formula: 
Value $=($ Function $*$ Quality $) /$ Cost, noticing that the cost is calculated for the desired modifications and adjustments when needed, a higher cost will result in lower value of flexibility.

Finally, the authors will analyse the results of the experts' evaluation, in order to develop the assessment model to be more realistic and applicable according to the Turkish context.

\section{RESULTS AND DISCUSION}

The forms of evaluation were distributed and explained to a group of active experts in Architectural design considering Turkish culture. The set was made of 10 experts active in design and planning in Turkish community for 10 years at least. In January 2020, they have filled the forms according to the methodology explained according value engineering assessment, and the authors gathered the results and calculated the medium of the results out of 10 . The results of each set of criteria are presented in the following tables. Accordingly, the general criteria assessment was calculated. Table 7 shows each criteria and sub criteria values as the result calculated following the explained methodology.

Table 2: Ranking results of "adaptability" sub criteria

\begin{tabular}{|c|c|c|c|c|}
\hline 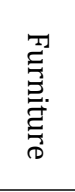 & $\begin{array}{l}0 \\
0 \\
0 \\
0 \\
0 \\
0 \\
0\end{array}$ & 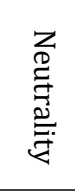 & 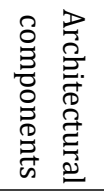 & 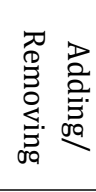 \\
\hline 1 & 9 & 8 & 9 & 10 \\
\hline 0.81 & 6.45 & 6.06 & 6.78 & 7.17 \\
\hline
\end{tabular}

Table 3: Ranking results of "multifunctionality" sub criteria

\begin{tabular}{|c|c|}
\hline Neutrality & Furniture \\
\hline 10 & 6 \\
\hline 7.77 & 5 \\
\hline
\end{tabular}

Table 4: Ranking results of "variability" sub criteria

\begin{tabular}{|c|c|c|}
\hline Opening & Model of circulation & Versatility/Modification \\
\hline 4 & 10 & 8 \\
\hline 2.96 & 7.96 & 6.29 \\
\hline
\end{tabular}

Table 5: Ranking results of "structure and construction" sub criteria

\begin{tabular}{|c|c|c|c|c|}
\hline $\begin{array}{c}\text { Position of wet } \\
\text { spaces }\end{array}$ & $\begin{array}{c}\text { load bearing } \\
\text { system }\end{array}$ & Divisions & Materials & $\begin{array}{c}\text { Technical } \\
\text { services }\end{array}$ \\
\hline 6 & 10 & 2 & 4 & 4 \\
\hline 5.54 & 10 & 2.11 & 3.61 & 3.85 \\
\hline
\end{tabular}


Housing Flexibility: A Framework for a Quantitative Evaluation Method due to Turkish Designers

Table 6: Ranking results of the main criteria of flexibility

\begin{tabular}{|c|c|c|c|}
\hline Adaptability & Multifunctionality & Variability & Structure and construction \\
\hline 7 & 4 & 3 & 10 \\
\hline 6.99 & 4.10 & 3.13 & 9.44 \\
\hline
\end{tabular}

Table 7: Calculated value of importance of each criteria and sub-criteria

\begin{tabular}{|c|c|c|c|c|c|c|c|c|c|c|c|c|}
\hline \multirow{2}{*}{ 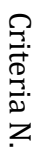 } & \multicolumn{2}{|c|}{ Main Criteria } & \multicolumn{9}{|c|}{ Sub Criteria } & \multirow[b]{2}{*}{ V. } \\
\hline & C. & V. & $\mathrm{C}$. & V. & C. & V. & C. & V. & C. & V. & C. & \\
\hline 1 & 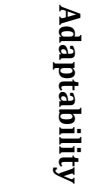 & 7 & 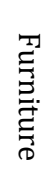 & 1 & 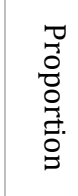 & 9 & 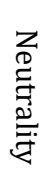 & 8 & 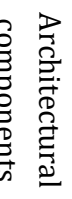 & 9 & 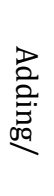 & 10 \\
\hline 2 & 冚 & 4 & 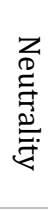 & 10 & 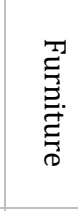 & 6 & & & & & & \\
\hline 3 & 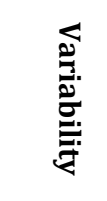 & 3 & 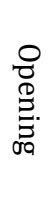 & 4 & $\begin{array}{ll}0 & \\
0 & \\
3 . & 3 \\
3 & 3 \\
2 & 0 \\
0 & 0 \\
0 & 0 \\
3 & \\
3 & \end{array}$ & 10 & 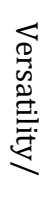 & 8 & & & & \\
\hline 4 & 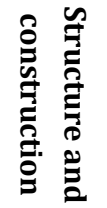 & 10 & 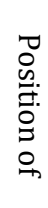 & 6 & 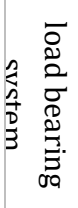 & 10 & $\begin{array}{l}0 \\
\text { : } \\
\text { : }\end{array}$ & 2 & $\begin{array}{l}\frac{3}{2} \\
\stackrel{2}{D} \\
\frac{2}{2} \\
\frac{0}{\infty}\end{array}$ & 4 & 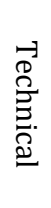 & 4 \\
\hline
\end{tabular}

When reviewing the results of the assessment, it is noticed that experts find "structure and construction" the most important factor, which controls and defines the flexibility of an architectural project design. Since the structural elements limit the possibility of any future modification and adaptation, it got the highest score. While "Adaptability" came as the second indicator, which seems logical since the whole aim of flexibility is the possibility of adaptation of the design according to the user's needs. Third comes "multifunctionality" which had a low score, almost equal to the fourth indicator of "variability". This raises some questions since the discussion with final users gave the impression that in Turkish culture multifunctionality is highly evaluated. This shows the difference understanding and evaluation of flexibility between designers and users, so it is of paramount importance to present the same assessment system to regular users to evaluate and compare the results, which the authors has already planned as a future work of this research. 


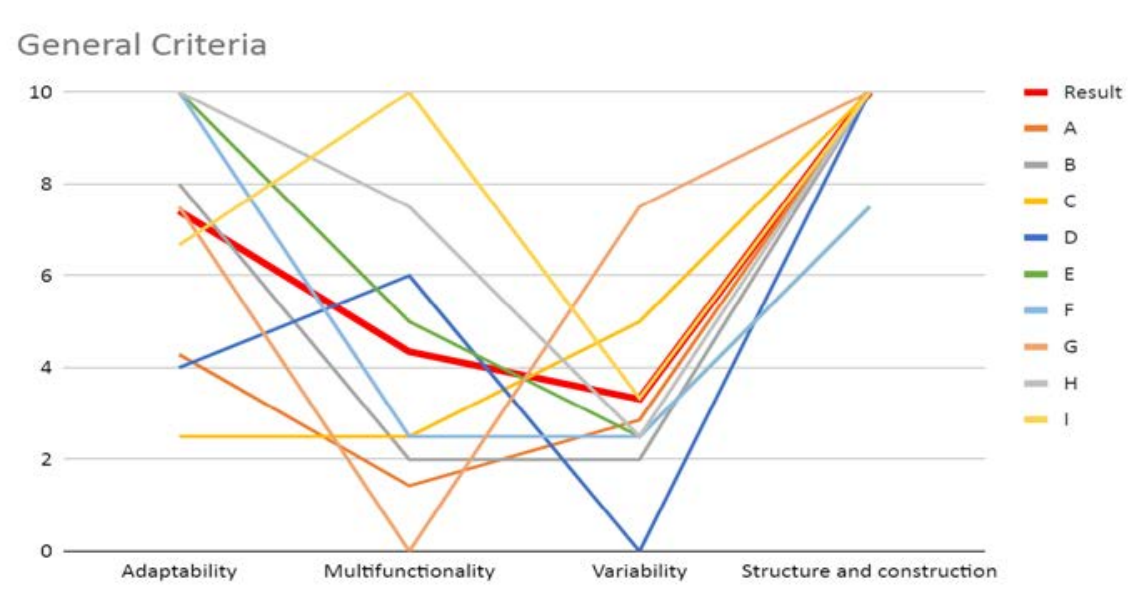

Although the main criteria shows the importance of structure, in the values of its sub criteria we notice that the load bearing systems were the most prominent indicator. It has a big difference compared to the divisions system, since the technical understanding of the experts evaluates again the limitation caused by structural elements with higher importance.

Looking deeply into the individual evaluation of experts shows a common agreement about the values of different criteria. Whereas in two of them we notice a big difference in the importance evaluation, namely in the multifunctionality there was a significant difference in views assessing the sub criteria.

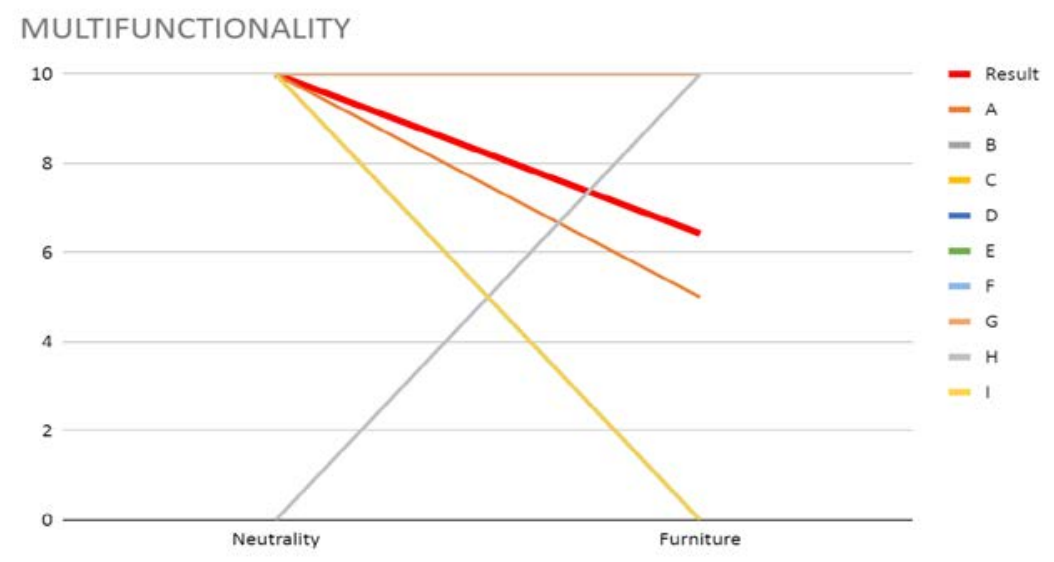

This situation has also been experienced for the divisions, sub criteria of the structure, where some of the evaluations considered it totally unimportant; others gave a considerable importance of this indicator.
Figure 5. Comparison of the flexibility main indicators relating different experts to the total evaluation

Figure 6. Comparison of the "multifunctionality" sub criteria relating different experts to the total evaluation 
Housing Flexibility: A Framework for a Quantitative Evaluation Method due to Turkish Designers

Figure 7. Comparison of the "structure and construction" sub criteria relating different experts to the total evaluation

Figure 8. Comparison of the "variability" sub criteria relating different experts to the total evaluation

\section{Structure and Construction Elements}

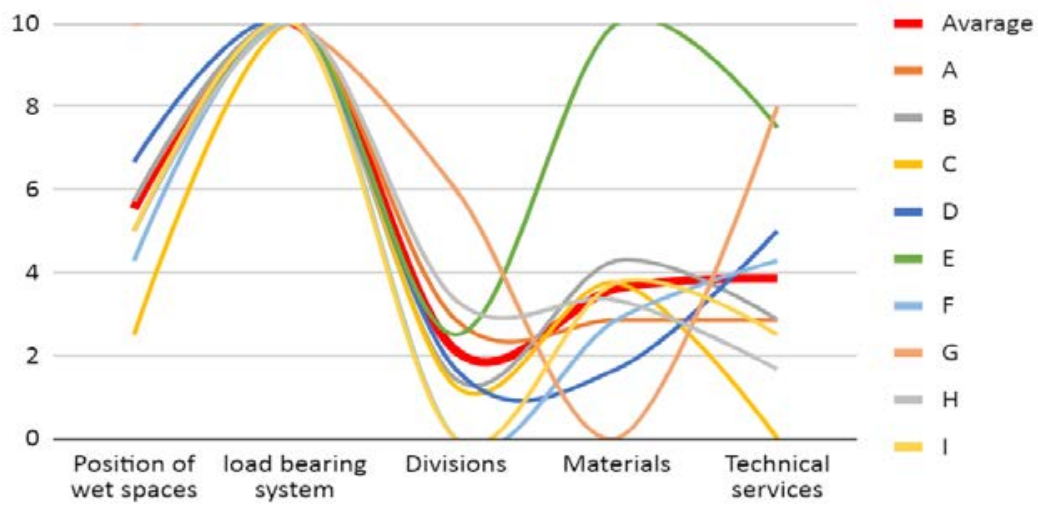

Again, the authors can notice almost a consensus agreement about the model of circulation importance as a criterion of variability, while coming to the versatility or modification possibility, it seems that the experts gave more ambiguous and diverse ranking.

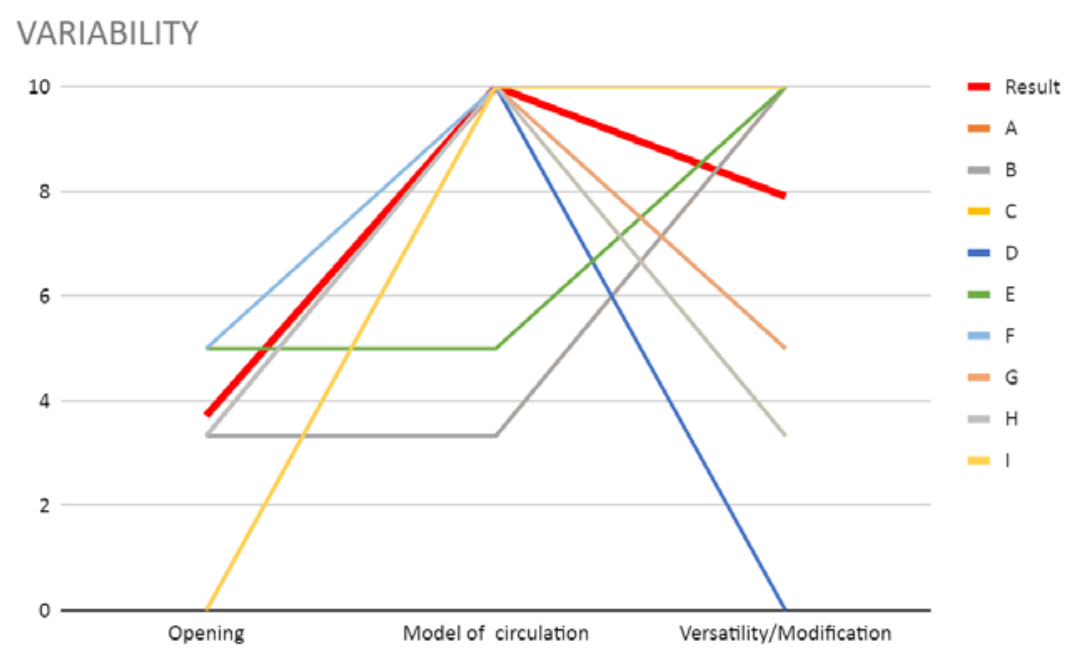

These differences can be related to the perceptive importance of flexibility in Turkish culture, but with lack of designers' sensitivity to tackle this issue. Particularly, due to the different definitions and the vague or absence of unified concept definition of flexibility. This is very clear when reviewing the diagram of adaptability assessment, where it looks stochastic and mixing the meaning of different criteria. Therefore, this research is trying to find a common unified definition of flexibility and its evaluation criteria and indicators. 


\section{ADABTABILITY}

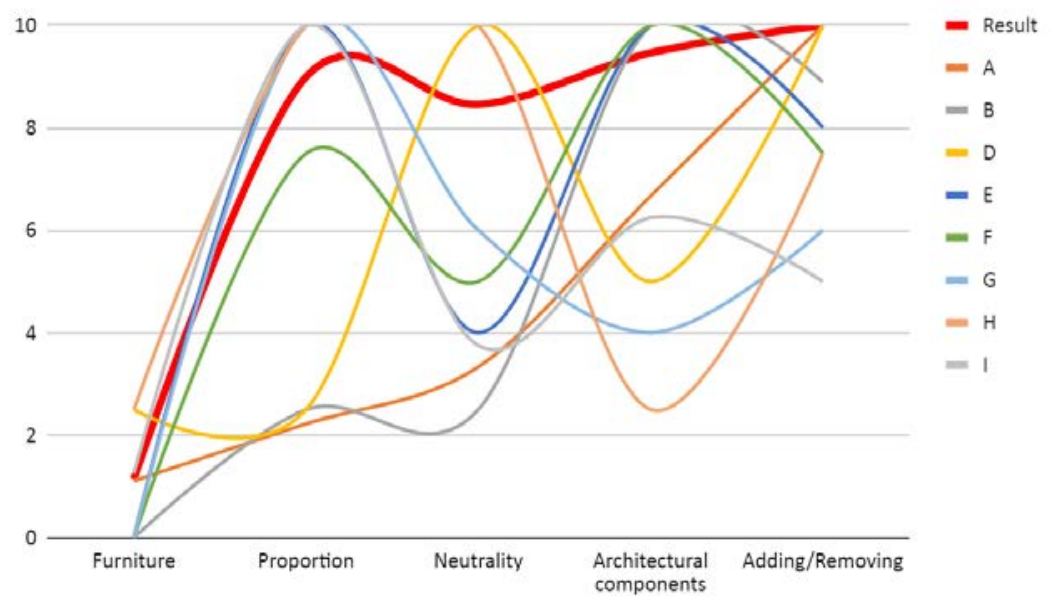

Figure 9. Comparison of the "adaptability" sub criteria relating different experts to the total evaluation

These results shed light onto the importance of understanding flexibility and the hierarchy between its principles from the Turkish designers' view; which have not been a real consideration in previous flexibility assessment systems. These systems have been directed according to the assumptions of the authors. The needed explanations between the indicators of flexibility to the experts have shown that an awareness has been provided regarding the need of flexibility. On the other hand, to ensure that this designers' vision responds to the users' expectation, the authors to are conducting a comparison study to define users' view first, and compatibility between both views second.

\section{CONCLUSION}

Flexibility creates an opportunity for an efficient and sustainable way of living for the inhabitants. Based on the presented evaluation system, which is established to define factors as a guidance for a flexible housing design. In order to adapt to the changing requirements of the users living in it, it is essential that the designers agree on a unified definition.

According to the aforementioned results of the designers meeting anonymously, it has been noticed that most of the experts have a different understanding of flexibility, but also have concurred on some indicators of it. All of the designers agree that structure and construction is the most important aspect of flexibility while divisions, which is a sub criterion of the structure and construction, have not played a crucial role. Even the experts were familiar with the terms of flexibility; sub criteria and assessment system were not an argument neither in norms nor in the practice as a real consideration when planning. Although they evaluated the main criteria differently giving a low ranking for some of them considered as an unimportant criterion, when evaluating the sub criteria of those low-ranked ones, they were evaluated with high rankings. After the explanation of the content, all the designers indicated that such a study would be very useful for the sustainability and efficiency of the housing design in Turkey. 
Housing Flexibility: A Framework for a Quantitative Evaluation Method due to Turkish Designers

In order to compromise the real needs, since there is no real agreement with the interviewed designers, the future studies of the researchers focus on the opinion of the users which can reveal their requirements by applying the same methodology. Comparing the user's requirements with experts' understanding will enable us to establish a clear evaluation system of housing flexibility. This is when the final system can be formed and published, and it might help to create an awareness for a clear understanding of the terminology of flexibility, and provides guidelines, which contribute to the implementation of flexible housing design from the point of view of Turkish society. The awareness provided with the study, has the potential to change the understanding of nowadays stability of the Turkish housing design. Especially after revealing the user needs of flexibility, inhabitants will be able to realise a shift to a more flexible housing design, which is necessary and possible. This study points out the "structure and construction" as the most important indicator of the flexibility which can stimulate a reviewing and rethinking process about the structure and materials of new housing in close future.

\section{ACKNOWLEDGEMENTS}

The Authors appreciate the collaboration of the experts for the development of criteria of flexibility evaluation in Turkey.

\section{CONFLICT OF INTEREST}

No conflict of interest was declared by the authors.

\section{FINANCIAL DISCLOSURE}

The authors declared that this study has received no financial support.

\section{ETHICS COMMITTEE APPROVAL}

Ethics committee approval was not required for this article.

\section{LEGAL PUBLIC/PRIVATE PERMISSIONS}

In this research, the necessary permissions were obtained from the relevant participants during the survey and in-depth interviews.

\section{REFERENCES}

Akalin, A., \& Yildirim, K. (2010). User interventions in Turkish mass housing. Open House International :, 35(1), 57-65.

Altaş, N., \& Özsoy, A. (1998). Spatial adaptability and flexibility as parameters of user satisfaction for quality housing. Building and Environment, 33(5), 315-323. https://doi.org/10.1016/s03601323(97)00050-4

Altman, I., \& Wohlwill, J. F. (2012). Human Behavior and Environment. Springer Science \& Business Media.

Beisi, J. (1995). Adaptable housing or adaptable people? Experience in Switzerland gives a new answer to the questions of housing adaptability. 
Architecture \& Comportement/Architecture \& Behaviour, 11(2), 139-162.

CABE. (2004). Housing Futures 2024. Built Environment, 11.

Connaughton, J. N., \& Green, S. D. (1996). Value Management in Construction: A Client's Guide (Construction Industry Research \& Information Association (CIRIA) (ed.)). (CIRIA).

Cristiana Cellucci, \& Michele Di Sivo. (2015). The Flexible Housing: Criteria and Strategies for Implementation of the Flexibility. Journal of Civil Engineering and Architecture, 9(7), 845-852. https://doi.org/10.17265/1934-7359/2015.07.011

Darke, J. (1982). The Design of Public Housing: Architects' Intentions and Users' Reactions. University of Sheffield.

De Paris, S. R., \& Lopes, C. N. L. (2018). Housing flexibility problem: Review of recent limitations and solutions. Frontiers of Architectural Research. https://doi.org/10.1016/j.foar.2017.11.004

Dirisamer, R., Kuzmich, F., Voss, W., \& Weber, J. P. (1976). Project Dwelling of Tomorrow. In Hollabruun, Austria',. Industrialisation Forum, 7(1), 1116.

Domenig, G. (1991). Wohnprojekt "Neufeldweg" in Graz/A. Deutsche Bauzeitschrift, 39(4), 492-502.

Estaji, H. (2017). A Review of Flexibility and Adaptability in Housing Design. International Journal of Contemporary Architecture, 4(2), 37-49. https://doi.org/10.14621/tna.20170204

Forty, A. (2002). Words and Buildings: A Vocabulary of Modern Architecture Adrian Forty. Journal of the Society of Architectural Historians, 61(1), 187. https://doi.org/10.2307/991831

Fricke, E., \& Schulz, A. P. (2005). Design for changeability (DfC): Principles to enable changes in systems throughout their entire lifecycle. Systems Engineering. https://doi.org/10.1002/sys.20039

Groak, S. (2002). The idea of building: thought and action in the design and production of buildings. Taylor \& Francis.

Habraken, N. J. (2019). Supports: an alternative to mass housing. Routledge.

Hasgül, E., \& Özsoy, A. (2016). Konut Tasarımında Esnekliğin Farklı Konut Tipolojileri Üzerinden Tartışılması. Tasarım + Kuram, 22(1), 69-79. https://doi.org/10.23835/tasarimkuram.560642

Hertzberger, H. (1991). Lessons in architecture. 010 publisher.

Idrissi, D. (2006). Anpassungsfähiges Wohnen: zur Flexibilitätdes Wohnens in der muslimischen Gesellschaft [Universität Stuttgart]. http://dx.doi.org/10.18419/opus-53

İSLAMOĞLU, Ö., \& USTA, G. (2018). MIMARI TasarimdaEsneklik Yaklaşimlarina KuramsalBir Bakiş. The Turkish Online Journal of Design Art and Communication, 8(4), 673-683. http://dergipark.gov.tr/tojdac/issue/39502/466005

Kendall, S. (1999). Open Building: An Approach to Sustainable Architecture. Journal of Urban Technology, 6(3), 1-16. https://doi.org/10.1080/10630739983551 
Housing Flexibility: A Framework for a Quantitative Evaluation Method due to Turkish Designers

Kiaee, M., Soltanzadeh, H., \& Heidari, A. (2019). Measure the flexibility of the spatial system using space syntax (Case Study: Houses in Qazvin). Bagh-e Nazar, 16(71), 61-76. https://doi.org/10.22034/bagh.2019.86874

Koman, İ., \& Eren, Ö. (2010). Flexible Design for Mass Housing in Turkey. Uludağ University Journal of The Faculty of Engineering, 15(1), 53-66. https://doi.org/10.17482/uujfe.36923

Koolhaas, R. (1998). La ciudad genérica. S,M,L,Xl. 1.

Leung, M. Y., \& Liu, A. M. M. (2003). Analysis of value and project goal specificity in value management. Construction Management and Economics. https://doi.org/10.1080/0144619032000065081

Mahdavinejad, M., Rezaei, S., Ebrahimi, M., \& Mostafa, S. (2012). Proposing a Flexible Approach to Architectural Design as a Tool for Achievement Eco-Friendly Multi-Purpose Buildings. Advanced Materials Research, 622623, 1856-1859. https://doi.org/10.4028/www.scientific.net/AMR.622623.1856

Male, S., Kelly, J., Fernie, S., Grönqvist, M., \& Bowles, G. (1998). Value Management: The value management benchmark: A good practice framework for clients and practitioners. Thomas Telford Ltd. https://www.icevirtuallibrary.com/isbn/9780727750013

Moharram, L. A. (1998). A Method for Evaluating the Flexibility of Floor Plans in Multi-Story Housing [University of Pennyslvania]. https://repository.upenn.edu/dissertations/AAI8018587

Nal, E. İ., \& Ünlü, A. (2009). Türkiye ' de afet sonras i kal i c 1 konutlarda esneklik kavram $\mathrm{n}$ i n de ğ erlendirilmesi. İTÜDERGISII, 8(2), 101-109.

NJ, E. (2009). Designing High-Density Cities: For Social and Environmental Sustainability. Routledge.

Rabeneck, A., Sheppard, D., \& Town, P. (1974). Housing Flexibility? Architectural Design, 43, 698-727.

Rajan, P. P. K., Van Wie, M. J., Wood, K. L., Otto, K. N., \& Campbell, M. I. (2003). Design for Flexibility: Measures and Guidelines. International Conference on Engineering Design, ICED03, 203-207. http://www.designsociety.org/design_for_flexibilitymeasures_and_guidelines.download.24032-2.pdf

Rapoport, A. (1982). The meaning of the built environment: a nonverbal communication approach. The Meaning of the Built Environment: A Nonverbal Communication Approach. https://doi.org/10.1016/07430167(86)90078-1

Saleh, J. H., Hastings, D. E., \& Newman, D. J. (2003). Flexibility in system design and implications for aerospace systems. Acta Astronautica. https://doi.org/10.1016/S0094-5765(02)00241-2

Schneider, T., \& Till, J. (2005). Flexible housing: opportunities and limits. Architectural Research Quarterly, 9(2), 157-166. https://doi.org/10.1017/S1359135505000199

Schneider, T., \& Till, J. (2016). Flexible housing. Routledge.

Slaughter, E. S. (2001). Design strategies to increase building flexibility. 
Building Research and Information, 29(2), 208-217.

Sposito, C. (2012). Identità , Flessibilità e Sostenibilità per un nuovo Social Housing. Techne, 4, 153-159.

Steger, B. (n.d.). Über Partizipation. Mitbestimmung bei Ottokar Uhl. Retrieved January 10, 2020, from http://www.parq.at/parq/sections/ research/stories/297/

Stephen, K., \& Jonathan, T. (2010). sidential Open Building (J. Teicher (ed.)). E \& FN Spon.

Till, J., \& Schneider, T. (2005). Flexible housing: The means to the end. Architectural Research Quarterly, 9(3), 287-296. https://doi.org/10.1017/S1359135505000345

Tuik. (2016). Nüfus ve Konut Araştırması 2011. http://www.tuik.gov.tr/PreHaberBultenleri.do;jsessionid=nz17W2ZZGn MPMkSDnhpqlFjwjrcTDKDV61rKmK420W46GyYy7h3r!671394295?id= 15843

Uhl, O. (1981). Ablesbare Partizipation'. Bauwelt, 72, 38.

Van der Voordt, T. J. M., \& Van Wegen, H. B. R. (2005). Architecture in use: an introduction to the programming, design and evaluation of buildings. Elsevier: Architecture Press.

Venturi, R. (1977). Complexity and Contradiction in Architecture (M. of M. Art (ed.)). Museum of Modern Art.

Zairul, Z., \& Geraedts, R. (2015). New business model of flexible housing. CIB W104 International Conference The Future of Open Building, Zürich, Switzerland, September 9-11, 2015; Authors Version, 2050. https://repository.tudelft.nl/islandora/object/uuid:397ec20e-5d42464c-85f3-b93e36d246b9?collection=research\#?

Zivkovic, M., \& Jovanovic, G. (2012). A method for evaluating the degree of housing unit flexibility in multi-family housing. Facta Universitatis - Series: Architecture and Civil Engineering. https://doi.org/10.2298/fuace $1201017 \mathrm{z}$

\section{Resume}

Hatice Kalfaoglu Hatipoglu works at Department of Architecture of AYBU as Asst.Prof. She got her BSc. and MSc and PhD degrees in Architecture and Planning at Vienna University of Technology. She worked in several architecture offices in Austria. Her current research interests are housing quality, flexible design in buildings, neighbourhood, urban design, sustainability, evaluation systems.

Salah Haj Ismail Architect. Ph.D. in Cultural Heritage. Worked as Architect in different countries, winning design competitions. Academically, worked as assistant professor in Syria, Italy and Spain published many researches and books in Arabic, English and Italian. Recently, works in Turkey at AYBU as associate professor. Research fields: Post crisis Development, Management of Cultural Heritage. 